\title{
Gypsum-bonded Investment and Dental Precision Casting (III) Composition of Investment for the Quick Casting Technique
}

\author{
Toshiko MORI ${ }^{1,2}$ and Farzaneh AGHAJANI ${ }^{2,3}$ \\ ${ }^{1}$ Department of Dental Biomaterials, College of Dentistry, Kyungpook National University, 2-188-1 Samduk-dong, Jung-gu \\ Daegu 700-412, South Korea \\ ${ }^{2}$ Biomaterials Science Unit, Faculty of Dentistry, The University of Sydney, 2 Chalmers Street, Surry Hills, NSW 2010, \\ Australia \\ ${ }^{3}$ Department of Dental Materials, Faculty of Dentistry, Tehran University of Medical Science, Tehran, Iran \\ Corresponding author, E-mail:mori@knu.ac.kr
}

Received January 13, 2004/Accepted March 19, 2004

\begin{abstract}
A simultaneous differential thermal analysis and thermogravimetry method previously established was used to estimate the composition of gypsum-bonded investment marketed for the quick casting technique. Three commercial investments of this type were heated to $700^{\circ} \mathrm{C}$ at $10^{\circ} \mathrm{C} / \mathrm{min}$ and the hemihydrate content was estimated by the mass decrease reached at $300^{\circ} \mathrm{C}$ after subtracting the mass decrease at $100^{\circ} \mathrm{C}$ as moisture content. The hemihydrate contents were between $25 \%$ and $30 \%$, which appears to be the range also chosen for the conventional gypsum-bonded investment of cristobalite type over 70 years by the industry. However, the new type of investment contained both cristobalite and quartz. The small sample size is a disadvantage of the present method but this can be overcome by more frequent use of the method by investigators.
\end{abstract}

Key words: Investment composition, rapid heating investment, DTA-TG

\section{INTRODUCTION}

It is not common to make reference to the composition of casting investment in our research. A simple method, which utilized simultaneous differential thermal analysis and thermogravimetry (DTA-TG), was reported to estimate the content of calcium sulfate hemihydrate incorporated in gypsum-bonded casting investment ${ }^{1,2)}$. The method found that the content of calcium sulfate hemihydrate was about $30 \%$ by weight in two conventional gypsum-bonded cristobalite investments, the oldest and more recent, giving an estimation for the refractory content of about $70 \%$ by weight ${ }^{2)}$. In the present study, the above method was applied to find the composition of investment recently marketed for the quick casting technique (hereafter, rapid heating investment).

\section{MATERIALS AND METHODS}

Table 1 shows three rapid heating investments analyzed in the present study. Each investment sample and $\alpha$-alumina reference material were kept in a desiccator over silica gel for at least $24 \mathrm{hr}$ before the DTA-TG measurement (Thermoflex, Rigaku Co., Tokyo, Japan). A quantity of $200 \pm 0.1 \mathrm{mg}$ was used for both sample and reference in each analysis. They were placed in two separate compartments of a platinum sample holder. Each compartment had a recess at the base to accommodate the hot junction of a thermocouple. The samples were heated to $700^{\circ} \mathrm{C}$ at a rate of $10^{\circ} \mathrm{C} / \mathrm{min}$. The TG display was $20 \mathrm{mg}$ full scale with an accuracy of $0.2 \%$. Mass changes were calculated at every $100^{\circ} \mathrm{C}$ as percentage change. Drying over silica gel does not completely remove the moisture adsorbed by calcium sulfate hemihydrate (hereafter, hemihydrate), especially in the case of dry-calcined $\beta$-hemihydrate ${ }^{1,2)}$. Based on this finding, the estimation of hemihydrate content was made from the mass decrease at $300^{\circ} \mathrm{C}$ after subtracting the mass decrease at $100^{\circ} \mathrm{C}$ as moisture content and then by comparing the result with the theoretical dehydration value of $6.25 \%$ of hemihydrate to anhydrite. As secondary information, peak temperature was also determined for each endothermic or exothermic reaction on the DTA curve with a display range of $\pm 25 \mu \mathrm{V}$. The temperature display was $1000^{\circ} \mathrm{C}$ full scale with an accuracy of $0.3 \%$. At least 5 samples were tested for each investment. Ambient laboratory conditions during the analysis were $21 \pm 1^{\circ} \mathrm{C}$ and 50 $\pm 10 \%$ relative humidity.

Table 1 Three rapid heating gypsum-bonded investments studied

\begin{tabular}{clc}
\hline Code & Name & Recommended w/p ratio \\
\hline $\mathrm{R} 1^{1}$ & Cristoquick II & 0.33 \\
$\mathrm{R}^{2}$ & Cristobalite PF & 0.35 \\
$\mathrm{R}^{3}$ & Cristobalite FF & 0.35 \\
\hline
\end{tabular}

${ }^{1}$ GC Corp. Tokyo, Japan

${ }^{2}$ Shofu Inc., Kyoto, Japan

${ }^{3}$ Noritake Co. Ltd., Nagoya, Japan 
Table 2 DTA-TG results of three rapid heating investments

\begin{tabular}{lccc}
\hline \multicolumn{1}{c}{ Material } & $\mathrm{R} 1(\mathrm{n}=6)$ & $\mathrm{R} 2(\mathrm{n}=5)$ & $\mathrm{R} 3(\mathrm{n}=5)$ \\
\hline Mass decreases (\%) & & & \\
$100^{\circ} \mathrm{C}$ & $0.04(0.04)$ & $0.00(0.00)$ & $0.19(0.01)$ \\
$200^{\circ} \mathrm{C}$ & $1.59(0.07)$ & $1.85(0.04)$ & $1.95(0.02)$ \\
$300^{\circ} \mathrm{C}$ & $1.60(0.07)$ & $1.85(0.04)$ & $1.96(0.02)$ \\
$400^{\circ} \mathrm{C}$ & $1.60(0.07)$ & $1.86(0.04)$ & $1.96(0.03)$ \\
$500^{\circ} \mathrm{C}$ & $1.60(0.07)$ & $1.86(0.05)$ & $1.96(0.03)$ \\
$600^{\circ} \mathrm{C}$ & $1.60(0.08)$ & $1.86(0.04)$ & $1.96(0.02)$ \\
$700^{\circ} \mathrm{C}$ & $1.60(0.07)$ & $1.86(0.05)$ & $1.96(0.02)$ \\
Peak temperature $\left({ }^{\circ} \mathrm{C}\right)$ & & & \\
1 st endotherm & $184(0.8)$ & $184(0.8)$ & $182(1.6)$ \\
2 nd endotherm & $255(0.4)$ & $250(0.7)$ & $233(1.5)$ \\
3 rd endotherm & $570(0.7)$ & $569(0.0)$ & $570(0.7)$ \\
Exotherm & $198(1.4)$ & $200(0.5)$ & $198(1.2)$ \\
Content of calcium sulfate hemihydrate (\%) & 25.0 & 29.6 & 28.3 \\
\hline
\end{tabular}

Values shown are average (standard deviation).

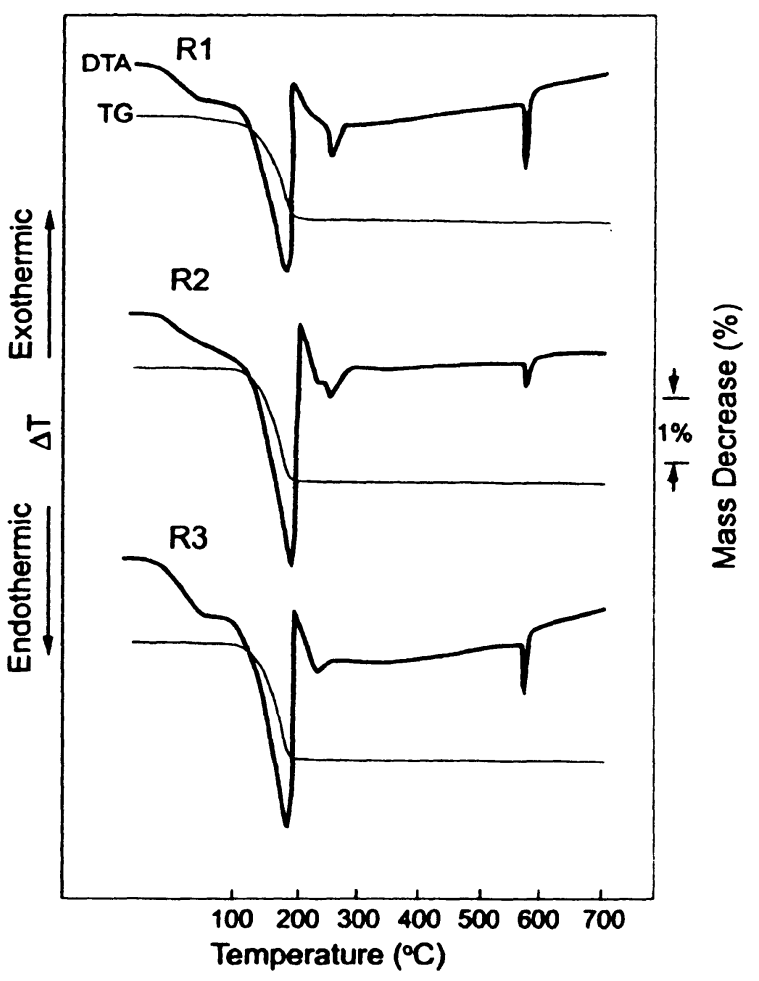

Fig. 1 Representative DTA-TG curves of three rapid heating investments. $\mathrm{R} 1=$ Cristoquick II (GC), $\mathrm{R} 2=$ Cristobalite $\mathrm{PF}$ (Shofu), R3=Cristobalite FF (Noritake).

\section{RESULTS}

Figure 1 shows representative DTA-TG curves of the three investments. Both DTA and TG curves are very similar for all materials. A large mass decrease, which was almost complete by $200^{\circ} \mathrm{C}$, corresponded with a large endothermic reaction. This was the only significant mass change, apparently due to the dehydration of hemihydrate. Table 2 summarizes results of the analysis. The mass decrease at $100^{\circ} \mathrm{C}$ ranged from nil (R2) to $0.19 \%(\mathrm{R} 3)$. This produced a small deflection on the DTA curve, most prominent with R3. The average peak temperature of the fist endotherm due to the dehydration of hemihydrate was almost same, $182^{\circ} \mathrm{C}$ or $184^{\circ} \mathrm{C}$, and an exothermic peak having an average peak temperature of $198^{\circ} \mathrm{C}$ or $200^{\circ} \mathrm{C}$ immediately followed the endotherm. Little mass decrease occurred after $200^{\circ} \mathrm{C}$, giving a constant at $300-700^{\circ} \mathrm{C}$ in each material. In this temperature range, two endothermic reactions appeared at about $250^{\circ} \mathrm{C}$ and $570^{\circ} \mathrm{C}$, indicating the $\alpha-\beta$ (low-high) inversion of cristobalite and quartz, respectively. The contents of hemihydrate calculated by the method described before were $25 \%$ (R1), $30 \%$ (R2) and $28 \%$ (R3) by weight.

\section{DISCUSSION}

The most extensive compositional analysis of gypsum-bonded investment was made on 38 commercial products in $1930^{3)}$. Their thermal expansion (TE) values were less than $1 \%$ due to the high $\beta$-hemihy drate (plaster) contents, between $30 \%$ and $50 \%$ with many products, and also due to the use of quartz. This survey also showed the possibility of achieving a higher $\mathrm{TE}$ value of $1.25 \%$ with an experimental investment by replacing quartz with cristobalite. Three years later, one of the authors further reported the replacement of $\beta$-hemihydrate $(25 \%)$ with $\alpha$-hemihydrate (dental stone) to achieve a TE value of $1.5 \%{ }^{4)}$. Since that time, the content of $\alpha$ hemihydrate seems to have remained in the range of about 25 to $30 \%$, the latter value being the estimation by the present method for the two investments of cristobalite type as mentioned before ${ }^{2)}$. The same range of hemihydrate inclusion was found on the three rapid heating investments analyzed in the present study. However, the refractory component, $75 \%$ 
(R1), $70 \%$ (R2) or $72 \%$ (R3), was a mixture of cristobalite and quartz in all materials, which is somewhat difficult to expect from their proprietary names. The inclusion of quartz was evident in the TE measurement of $\mathrm{R} 1$ and $\mathrm{R} 2$ under both general and rapid heating conditions ${ }^{5)}$.

The previous analysis ${ }^{2)}$ showed the possibility of using both $\alpha$-hemihydrate and $\beta$-hemihydrate in the oldest commercial gypsum-bonded investment of cristobalite type, which dates back as far as 1934 to a report by Van Horn ${ }^{6)}$. The relatively large mass decrease of $0.19 \%$ at $100^{\circ} \mathrm{C}$ in $\mathrm{R} 3$, even after drying over silica gel, leaves this possibility of $\beta$-hemihydrate inclusion, although in this case the exothermic peak should appear at around $350^{\circ} \mathrm{C}$ under the same analytical conditions ${ }^{1)}$. The inclusion, however, could be insignificantly low, as the recommended water/ powder ratio of $\mathrm{R} 3$ is not particularly higher than those of the other two investments. Furthermore, even with significant inclusion of $\beta$-hemihydrate, its sluggish transformation from III - $\mathrm{CaSO}_{4}$ to II-CaSO could result in an unnoticeable size of exotherm. While the exotherm due to this transformation in $\alpha$-hemihydrate was clearly shown at about $200{ }^{\circ} \mathrm{C}$ (Fig. 1) due to its more rapid reaction than in $\beta$ hemihydrate, it is an impossible task to determine the ratio of the two types of hemihydrate existing in gypsum-bonded investment by DTA.

The primary aim of the present study was to apply the DTA-TG method previously established to estimate the composition of three rapid heating investments. The use of the mass decrease at $300^{\circ} \mathrm{C}$ was proved to be appropriate again, as there were no mass changes above this temperature. The analysis, however, also provided a fresh insight into the role of gypsum binder in this casting technique; despite the higher hemihydrate content (30\%) in R2 in comparison with that in R1 (25\%), the former gave a higher average TE value of $1.93 \%$ against $1.72 \%$ in the latter ${ }^{5)}$. Accumulation of basic data will benefit us in further understanding of investment materials, as this example demonstrates.

One of the disadvantages of the present DTA-TG method is that the analysis is made on a small sample size. While this is a common DTA-TG technique, even distribution of investment components in the parent material must be assumed upon the adoption of data obtained. This disadvantage can be overcome by more frequent use of the present method by investigators.

\section{REFERENCES}

1) Mori T. Study of gypsum-bonded casting investment, Part 1. Aust Dent J 1993; 38: 220-224.

2) McAloon J, Mori T. Study of gypsum-bonded investment, Part 2. Aust Dent J 1993; 38: 306-308.

3) Taylor NO, Paffenbarger GC, Sweeney WT. Dental inlay casting investments: Physical properties and a specification. J Am Den Assoc 1930; 17: 2266-2286.

4) Sweeney WT. Cristobalite for dental investments. J Am Den Assoc 1933; 20: 108-119.

5) Mori T, Aghajani F. Gypsum-bonded investment and dental precision casting (II) Investment for the quick casting technique. Dent Mat J 2003; 22: 521-531.

6) Van Horn CS. What constitutes efficacy in dental inlay casting? Dent Cosmos 1934; 76: 511-523. 